\title{
الأحكام القانونية للجرف القاري في القانون الدولي
}

\section{د. هادي نعبم المالكي}

مقدمة

الجـرف القـاري هـو اصطلاح مستعار مـن علـم الجيولوجيـا حيـث لوحظظ أن السـاحل

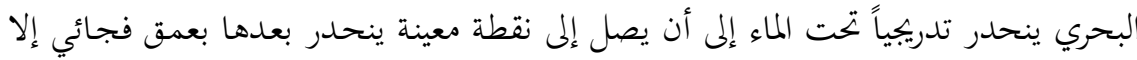

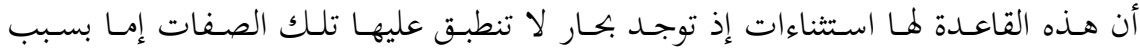

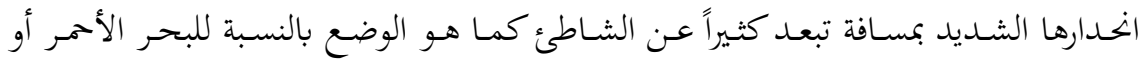

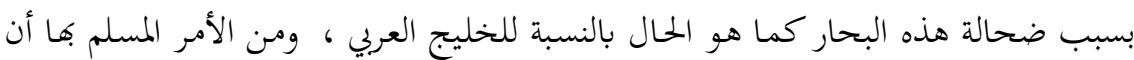
حرية البحار العالية تشكل مبدأ أساسياً وقاعدة من قواعد القانون الدولي العام المجمع عليها

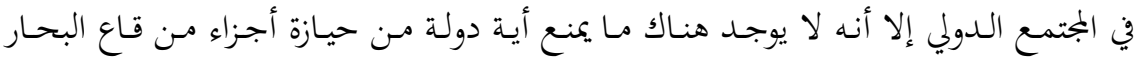

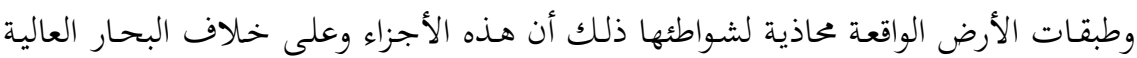
يمكن إدخاها في الحيازة المادية للدول طالما كانت هذه الحيازة لا يترتب عليها أي ضرر للدول الأخرى ولا تعرقل الملاحة الدولية ـ ويقصد بالجرف القاري ذلك الجزء من اليابسة الموجود في قاع البحر وما تحته من طبقات وقد كان ظهوره من نتيجة التقدم العلمي الذي لابس الحرب لهرب العالمية الثانية إلى جانـب تطور وسـائل البحثث والتنقيـب والاستغلال التي عرف الإنسـان

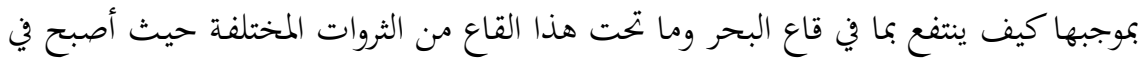

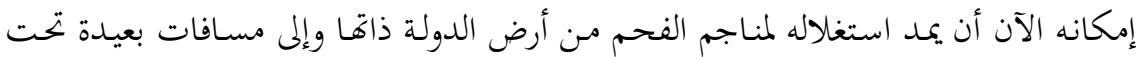

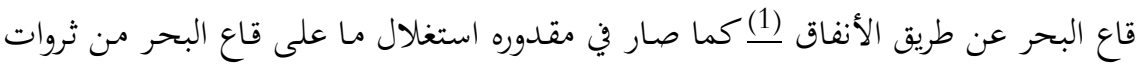
إلى جانب مـا تحت هذه القـاع من مختلف المعادن والوقود هذا فضلاً عما ظهر من الأفكار

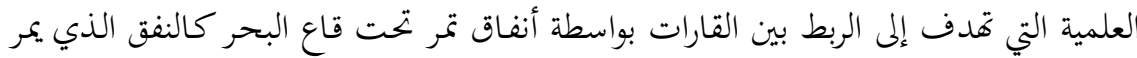

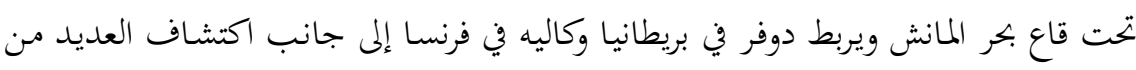

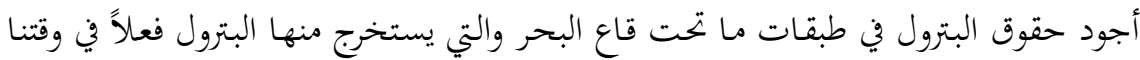


لقـد كان مـن نتيجـة تلك الاكتشـافات العلميـة أن أخـذت الدول تعلن وتؤكد حقوقها الوطنيـة في أن قـاع البحـــر والتربـة الجوفيـة لـلأرض تحتـه إنما تخضـع للسـيادة الوطنيـة للـدول الساحلية لأغراض الاستثمار وبهذا نشأت فكرة الجرف القاري ودخلت حيز القانون الدولي وهي تعني ذلك الانحدار الخفيف في قاع البحر والذي يوجد متصلاً بشواطئ الدولة الساحلية وبدأ اهتمام الدول بوضع الجرف القـاري عند التقدم التقني الذي كشف عن وجود ثروات هائلة من المعادن والبترول في مساحات هذا الجرف القاري وتعتبر المعاهدة الموقعة بين بريطانيا وفنزويلا عام 1942م من أجل تقسيم المنطقة المغمورة بين فنزويلا وجزيرة توباجو في خليج (Paria)

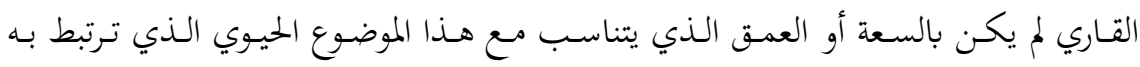
مصالح العديد من دول العالم (3) ـ ولما كان هذا الموضوع لم يسبق أن تم تنظيمه تنظيماً قانونياً فيما بين المجموعة الدولية نظراً لحداثته فقد أخذات الدول المختلفة ومنذ هاية الحرب العالمية الثانيـة تؤكـد سـيادتا المطلقـة على جميـع أجـزاء منـاطق الجـرف القـاري الكائنـة على امتـداد شواطئها إلى جانب تبعية هذه المناطق لها وكان ذلك عن طريق التصريحات الانفرادية وكان أول هذه التصريحات هو إعلان الرئيس ترومـان في 1945/9/28م (4) وإن كان قـد سبقه في ذلك الوقت إعـالان رئيس جمهوريـة الأرجنتـين الذي قرر ملكيـة الأرجنتـين لكل الثروات المعدنية الكائنة تحت قاع سطح الجرف القاري (5) وقد جاء في إعلان ترومان أن موارد الثروة في قاع البحر العالي ومـا تحته في الجزءء الملاصق لشواطئ الولايات المتحـدة الأمريكية يخضع

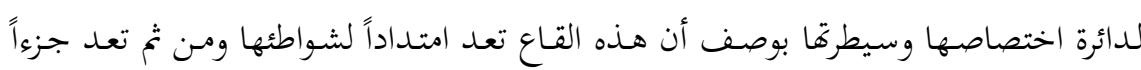

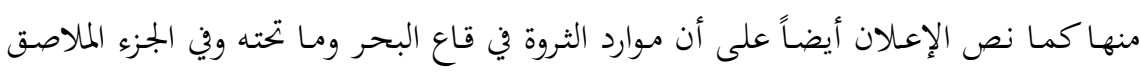
لشواطئ الولايات المتحدة الأمريكية يخضع لولايتها وسيطرتا مؤكداً في ذلك حاجة الولايات المتحدة الأمريكية إلى الحصول على البترول والموارد المعدنية الأخرى في المناطق البحرية المشار إليها والملاحظ على الإعلان أنه استند إلى عدة مبررات تتصل في ذلك التقدم التقني والعلمي الذي أحرزته الولايات المتحدة الأمريكية بما مكنها من استكشاف واستغلال الثروات الموجودة في قاع الجرف القاري الملاصق لبحارها الإقليمية مع تزايد احتياجاهـا لثروات بترولية ومعدنية

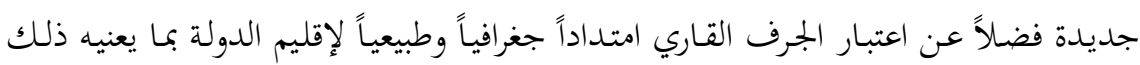


مـن ضـرورة وضع تنظيم يقوم على تأكيد اختصاص الدولة السـاحلية في مباشـة الاستغلال الأمثل لتلك الثروات وعلى الرغم من أن إعلان ترمـان لم يتضمن أي تحديد للحد الحنارجي للجرف القاري بما يضمن تعيين نطاق ولاية الدولة الساحلية على الموارد والثروات الموجودة في جرفها القاري فإنه كان لصدور الإعلان أثر إيجابي في مجال استخدام البحار وذلك بالنظر إلى ما ترتب عليه من مسارعة العديد من الدول إلى إصدار تصريحات وإعلانات مشابهة قاربت في مجموعها الخمسـين في ذلك الوقت ، وفي الشـرق الأوسط أخـذت الدول العربية وإيران بإصـدار إعلاناتها الخاصـة بكل منهـا والتي تحـدد سيادتا على الجـرف القـاري الذذي يقابـل

( $\left.{ }^{6}\right)$. سواحلها

وإذا كانت الدول قد لجأت إلى طريقة الإعلان الانفرادي من جانب واحد لتأكيد تبعية مناطق الجرف القاري لها إلا أنه يلاحظ أن كافة هذه الإعلانات ولو أها كانت تعتمد على إلى

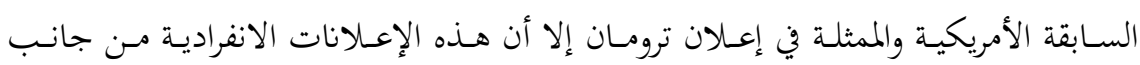
الدول لم تحدد طبيعة هذه التبعية إلى جانب أهما لم تحدد تحديداً دقيقاً المسافة التي تمتد إليها تبعية قاعا البحر وما تحته إذ لجأت جميع هذه الإعلانات إلى تقديرها بأها المسافة الخارجة عن

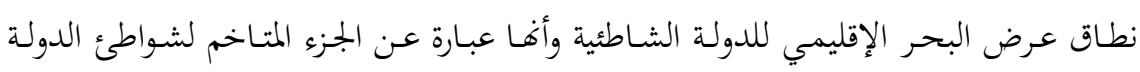
الساحلية وقد ترتبت على ذلك ظهور مشكلة قانونية لم يتوصل إلى حل لها إلا بإبرام اتفاقية

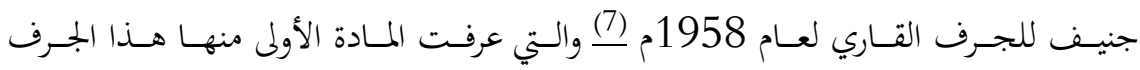
بأنه،"، ..قاع البحر ومـا تحته مـن طبقـات في المنـاطق البحرية المجاورة للشـاطئ الكائنة خـارج منطقة البحر الإقليمي إلى حيث يصل عمق المياه إلى مائتي متر أو إلى أبعد من ذلك متى كان

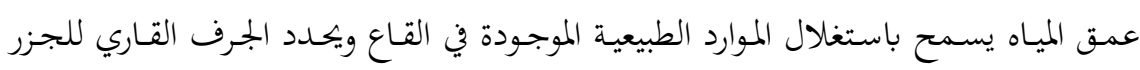
بنفس الطريقة السابقة.... '. .

\section{المبحث الأول: تعريف الجرف القاري}

يمكن القول بصفة عامـة أن الجـرف القـاري هو ذلك الجزء مـن اليابسة المغمور والذي

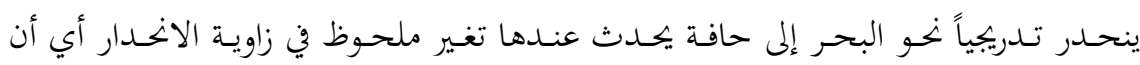

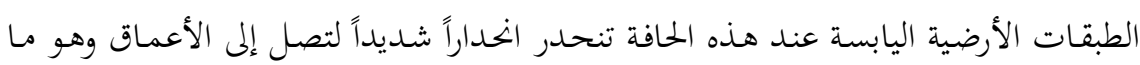
يطلق عليه الحد القاري وعلى هذا فإنه يوجد اتصال بين الجرف القاري وهو ذلك الجزء مـن 
اليابسة الموجود تحت سطح البحر والجزء الآخر المكمل له الموجود أعلى سطح المياه ، فالجرف القاري إذاً هو جزء من اليابسة ولو أنه مغمور بمياه البحر ولما كان الجرف القاري يبدأ تواجده حيث تنتهي المياه الإقليمية ذلك أنه يوجد بجوار المياه الإقليمية من هذا نصل إلى أن الجرف إلى القاري هو ذلك الجزء مـن الطبقات الأرضية المنحدرة والمتصلة بأرض الدولة والواقعة في قاع أعـالي البحـار بجـوار الميـاه الإقليمية للدولة ـ وقـد عرفت لجنة القـانون الدول عـام 1951م

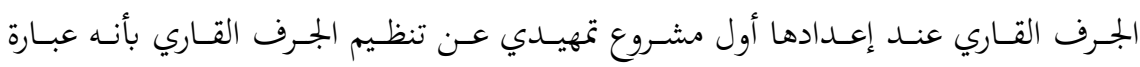
عن" ،...مناطق ما تحت قاع البحر وقاعه الكائنة تحت سطح البحر والمتاخمة للسواحل والتي تقـع خـارج نطـاق الميـاه الإقليميـة حيـث يسـمح عمـق الميـاه التي تعلوهـا باسـتغلال المصـادر الطبيعية الموجودة عند قاع البحر وتحته ...' . . وقد أعيد النظر في التعريف السابق في الدورة الخامسة للجنة القانون الدولي لعام 1953م حيث أهمل معيار الاستغلال وحل محله معيار العمق البالغ مائتي متر ويرجع ذلك التعديل إلى الانتقادات التي كانت قد تقدمت بها بعض الحكومات وإلى مـا توصلت إليه اللجنة مـن أن التعريـف السـابق كانـت تنقصـه في الواقع الدقـة اللازمـة والتي مـن شـأهفا أن تـؤدي إلى قيـام منازعات لا حصر لما وقد كان رأي اللجنة أن في معيار المائتي متر ما يكفي لتلبية احتياجات الأغراض العلمية السائدة في ذلك الوقت وربما لفترة طويلة بالنسبة للمستقبل ومما حث اللجنة

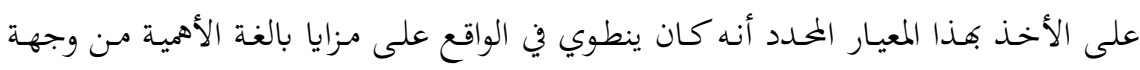
نظرها خاصة فيما يتعلق بقياس الجرف القاري بين الدول المتجاورة أو الدول المتقابلة إلا أن اللجنة كانت قد توقعت أن يسفر التقدم العلمي في المستقبل عن إتاحة الفرصة للاستغلال عند عمق أكثر من مائتي متر وفي هذه الحالة يجب أن يعاد النظر في هذا المعيار إلا أن اللجنة كان من رأيها أنه من المستحسن تماماً في هذا الوقت إيباد معيار محدد (8) وفي الدورة الثامنة للجنة القانون الدولي طالب بعض الأعضاء بضرورة تعديل المواد التي سبق أن توصل إليها في

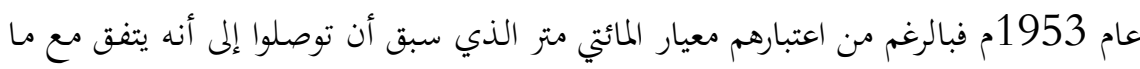
تقتضيه المتطلبات العلمية في الظروف السائدة آنذاك إلا أهمم لم يوافقوا إلى إضـافة نص يمنع استغلال الجرف القاري عند عمق يزيد عن مائتي متر ولو كان مثل هذا الاستغلال ممكناً من الناحية العلمية ذلك أفم كانوا يرغبون في الاعتراف بزيادة حد استغلال ما تحت قاع البحر 
وقاعه إلى عمق أكثر من مائتي متر إذا ثبت أن مثل هذا الاستغلال ممكن من الناحية التقنية

وأخيراً استقر الرأي في مؤتمر جنيف لقـانون البحار الذي عقد في مـارس عـام 1958م على تعريـف الجـرف القـاري بأنه ،"...قـاع البحـر ومـا تحته مـن طبقـات في المنـاطق البحريـة المجاورة للشاطئ الكائنة خارج منطقة البحر الإقليمي إلى حيث يصل عمق المياه مائتي متر أو إلى أبعـــ مـن ذلـك مـتى كـان عمـق الميـاه يسـمح باسـتغلال المـوارد الطبيعيـة الموجـودة في القاع...." ويحدد الجرف القاري للجزر بنفس الطريقة السابقة ومما بتحر الإشارة إليه في هذا

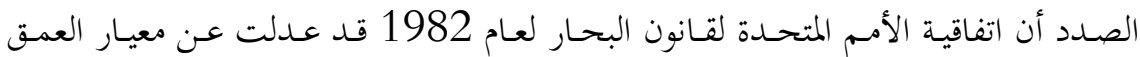
الذي كان محدداً بمائتي متر أو القدرة على الاستغلال كمـا ورد في اتفاقية جنيف إلى الأخذذ بالمفهوم الجغرافي والجيولوجي للجرف القاري وهكذا نصت المادة (76) مـن تلك الاتفاقية على أن"، .. يشـمل الجمرف القـاري لأي دولة سـاحلية قاع وباطن أرض السـاحات المغمـورة التي تمتد إلى ما وراء بحرها الإقليمي في جميع أنحاء الامتداد الطبيعي لإقليم تلك الدولة البري حتى الطرف الخارجي للحافة القارية أو إلى مسافة مائتي ميل بحري من خطوط الأساس التي يقاس منها عرض البحر الإقليمي إذا لم يكن الطرف الحنارجي للحافة القارية يمتد إلى تلك المسافة... ”’ وهكذا يشمل الجرف القاري للدولة الشاطئية قاع البحر وما تحته فيما وراء بحرها الإقليمي على طول الامتداد الطبيعي للإقليم البري لهذه الدولة حتى الحافة الخارجية للهامش القـاري أو حستى مسـافة مـائتي ميل بحــي مـن خطوط الأسـاس التي يبــأ منهـا قيـاس البحـر الإقليمي إذا كانت الحافة الخارجية للهامش القاري توجد على مسافة أقل وإذا وجدت الحافة الخارجية للهامش القاري على بعد أكثر من مائتي ميل فقد نصت الاتفاقية على أن الجـرف القـاري يمكن أن يمتد إلى مسافة لا تزيـد عن مـائتي ميل من خطوط الأسـاس التي يبـأ منها

$$
\text { قياس البحر الإقليمي (10) . }
$$

ومسن الملاحظ أن الهـامش القـاري يتـألف مـن قاع البحر وباطن الأرض للجـرف منحـدر الارتفاع ولكنها لا تشـمل القـاع العميق للمحيطات بما فيها مـن ارتفاعات في المحيطات ولا باطن أرضها ومن هذا المنطلق فإن لكل دولة الحق في جرف قاري يتحدد بمسافة مائتي ميل بحري إذا كانت الحافة الخارجية للهامش أقل مـن هذه المسـافة أو أزيـد مـن مائتي ميل بحري 
وحتى ثلاثمائة وخمسون ميلاً بحرياً إذا تعدى الهامش القاري مسافة المائتي ميل على أنه يجب أن نـذكر هنـا أن الدولة التي يمتـد جرفها القـاري إلى أبعـد مـن مـائتي ميـل بحــي تلتزم بـدفع مساهمات نقديـة أو عينيـة عن استغلال مـوارد الجـرف القـاري مـا بين مـائتي ميل إلى ثلاثمائة وخمسين ميلاً بحرياً أي مسافة مائة وخمسين ميلاً بحرياً تتراوح من (1\%) إلى (7\%) من قيمة أو حجم الإنتاج وتقدم هذه المساهمات إلى السلطة الدولية التي تتولى توزيعها على دول العالم مع الأخذ في الاعتبار مصاح الدول النامية والدول غير الساحلية (11) ولا شك أن أن السماح بالجـرف القـاري فيمـا وراء المـائتي ميل يشـكل بعض الاقتطـاع مـن المنطقـة الخاضعة للـتراث المشترك للإنسانية (12) وإن كانت الاتفاقية قد قررت كنوع مـ الحلـ التوفيقي التزام الدول

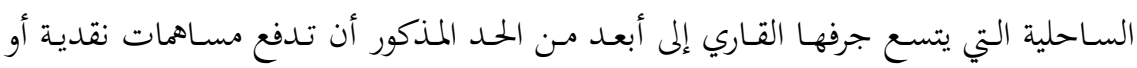

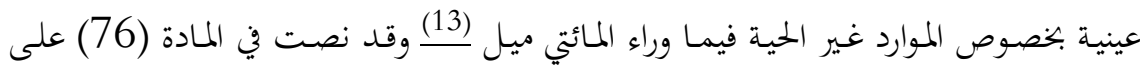
إنشاء لجنة لتعيين حدود الجـرف القاري فيما وراء المائتي ميل بحري ومـن الملاحظ أن تحديد الجرف القتاري بين الدول المتقابلة أو المتجاورة يجـب أن يتم عن طريق الاتفاق وفتـاً للقـانون الدولي مـن أجل الوصول إلى حل عادل وإذا لم يتوصل أطراف النزاع إلى حل له فقد نصت

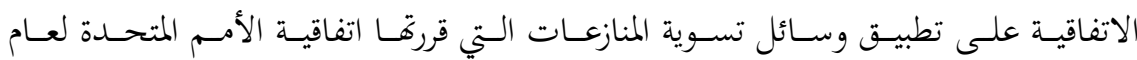
(14) 1982

\section{موقف القضاء الدولي من الامتيازات البترولية السابقة على ظهور فكرة الجرف القاري :}

سبق أن توصلنا إلى أن ادعاءات الدول بحقوقها السيادية على جرفها القاري لم تظهر إلا

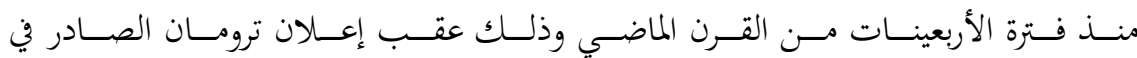
1945/9/28م ولقد أدى ذلك إلى إثارة العديد من المنازعات بين شركات البترول والدول المانحة للامتيازات البترولية وتدور تلك المنازعات حول مطالبة تلك الشركات باستخراج البترول الواقع في منـاطق الجـرف القـاري للدولـة المانحة باعتبـاره داخـلاً في نطاق الامتيـازات البتروليـة الممنوحة لها وقد تواترت أحكام محاكم التحكيم على الحكم بأن الامتيازات الممنوحة في الفترة السابقة لظهور فكرة الجرف القاري لا تشمل استخراج البترول من الجرف القاري ومن أمثلة ذلك قرار التحكيم الذي صدر في النزاع بين إحدى شركات البترول وإمارة أبوظبي فقد حدث

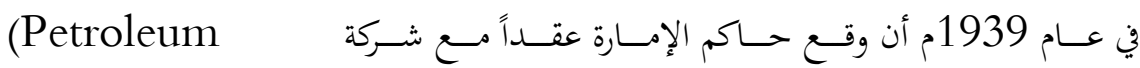


Development Trucial Coast Ltd.)

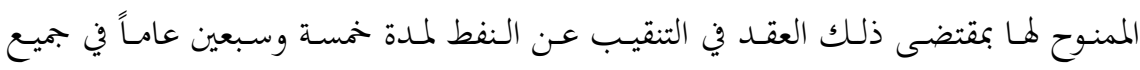

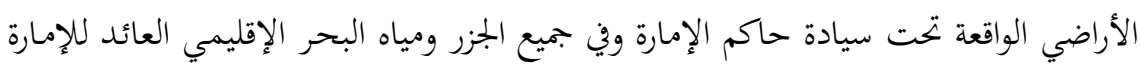

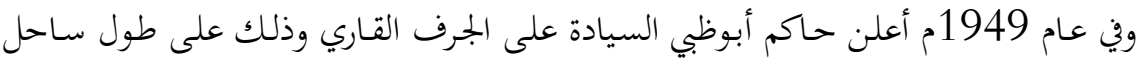

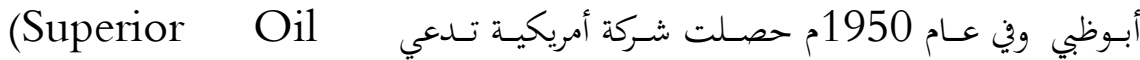

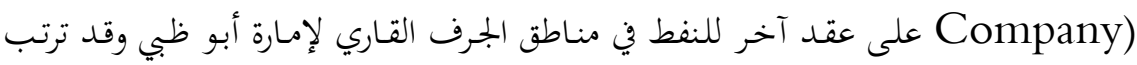

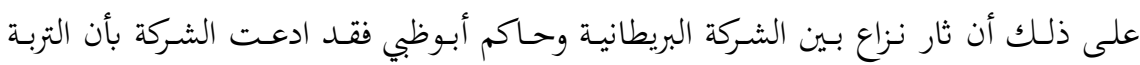

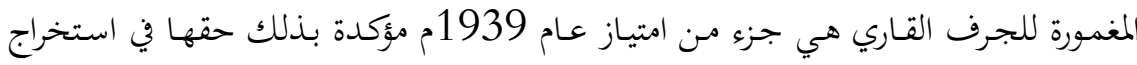

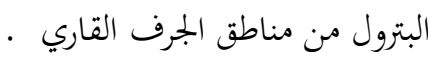

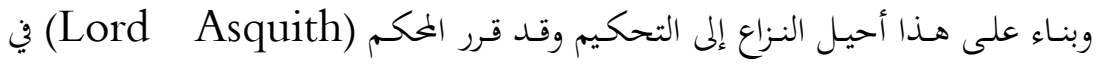

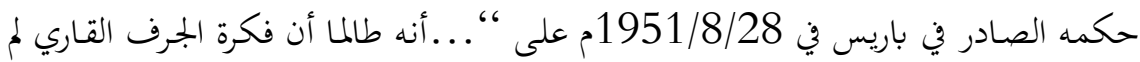

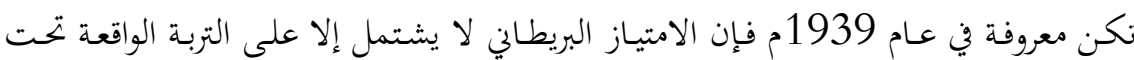

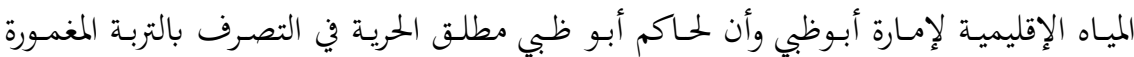
للجرف القاري عن طريق منح امتياز ثان وبذلك فإن ادعاء الشركة البريطانية بالمطالبة بامتياز

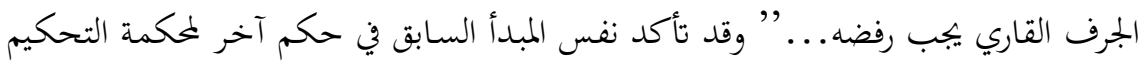

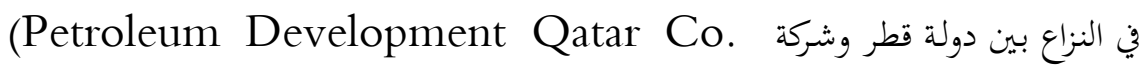

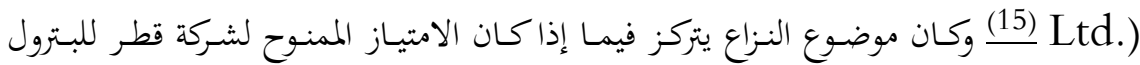

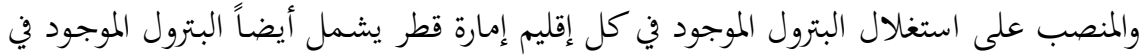

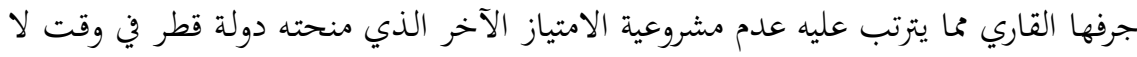

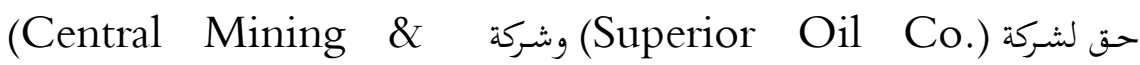
Investment Corporation Of London)

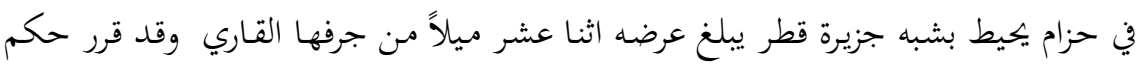

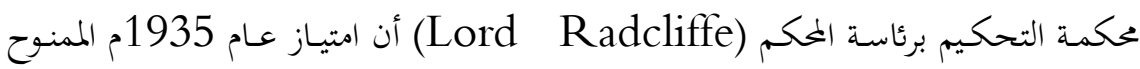

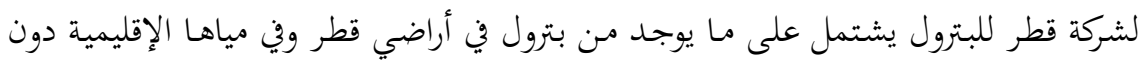
الجرف القاري (16 لثركة للبتول ينتصل ). 


\section{المبحث الثاني: تحديد الجرف القاري}

بالتمعن في التعريـف السـابق للجـرف القـاري والذي أتـت بـه اتفاقيـة جنيـف في مادتها

الأولى نجد أها اشترطت لكي يعتبر هذا الجزء المغمور من أرض الدولة جرفاً قارياً لها يجب أن لا يزيد قدر الخفاضه عن مستوي سطح المياه التي تغمره على مائتي متر والحكمة مـن وضع هذا الشرط أنه إذا زاد قدر الانخفاض على ذلك فإنه سوف يتعذر استغلال القاع أو ما تحته مـن طبقـات نتيجـة لظروف الطبيعة الجغرافيـة والبحريـة التي تلابس الاستغلال العملي لهذه المنـاطق وكان مـن الطبيعي (17) أن يوجـه إلى هـا المعيـار الذي أتـت به اتفاقيـة جنيف عـدة انتقادات في الوقت الحاضر ذلك أنه أصبح ناقصاً وغير كافٍ لكي يهكم الأوضاع المتغيرة في المجتمع الدولي فتحديد العمق المسموح بالاستغلال فيه بمائتي متر لا يتفق في الواقع مع ما هو جار عليه العمل حالياً إذ بتحاوزت الدول الآن هذا المدىى بشكل كبير ومن ناحية أخرى فإن تعريف الجرف القاري السابق ذكره والذي أتت به اتفاقية جنيف لعام 1958م يعتريه بعض الغموض من حيث تحديد الجرف القاري أفقياً وهو ما دفع البعض إلى القول بأن هذا التعريف لا يسمح بالامتداد الأفقي للجرف القاري تحت أعالي البحار إلى مالا فاية طالما أن الاتفاقية في مادتها الأولى سابقة الذكر أشارت إلى أن الجـرف القـاري يوجد في المناطق البحرية المجاورة

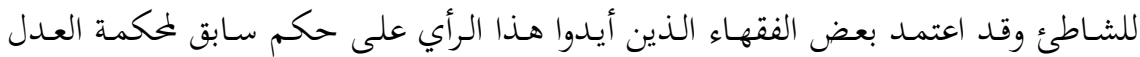
الدوليـة كـان قــ صـدر في عـام 1951م في قضــية المصـايد النرويجيـة البريطانيـة وقـــ جـاء

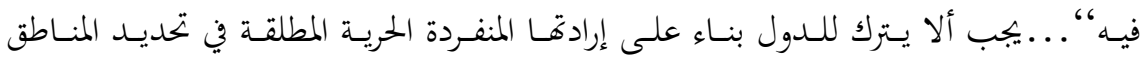
البحريـة....” (18) وعلى عكس الرأي السـابق نادى البعض الآخـر مـن الفقهاء بأن المـادة الأولى مـن اتفاقية الجـرف القـاري تسمح بأن يكـون الجـرف القـاري إلى مـالا هاية تحت ميـاه البحار العالية وقد اعتمد هذا الفريق من الفقهاء على حكم آخر ملكمة العدل الدولية كان قد صدر في قضية الجرف القاري لبحر الشمال عام 1969م (19) والذي جاء فيه أن كلمة المجاورة الواردة بالمادة الأولى من اتفاقية الجرف القاري لعام 1958م تفيد القرب بالمعنى الواسع وعلى هـا فإن التعريف الذي أتت بـه اتفاقية جنيف يشير إلى قرب ال القاري مـن الدولة

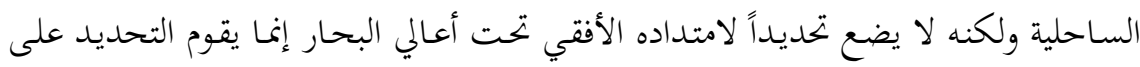


أساس العمق فقط وقد وجد هذا الفريق الثاني من الفقهاء في هذا الحكم سنداً لرأيهم السابق والذي يسمح بأن يكون الجرف القاري إلى مالا غاية تحت مياه البحار العالية(20) . وقـد ظهر الخـلاف بـين الـدول التي تنـادي بأن الجـرف القـاري يمتـد إلى مـالا هايـة وبين الدول التي تنادي بعكس ذلك في المؤتمر الثالث لقانون البحار ذلك أن الدول التي لديها جروف قارية عريضة كالولايات المتحدة الأمريكية والهند وإندونيسيا طالبت بأن يمتد جرفها القاري حتى الحافة الخارجية في حين ترى الدول ذات السواحل الضيقة والدول المغلقة بألا يزيد عرض الجـرف القـاري عن مـائتي ميل بحري (21) وذلك حتى يكون هنـاك منـاطق كافية للجهاز الدولي المزمع إنشاؤه لاستغلال قاع البحار العالية التي أصبحت تراثاً مشتركاً للبشرية وتوزيع عائدها على جميع الدول وخاصـة النامية منها. وقدـ حاولت اتفاقية الأمـم المتحـدة لقـانون البحـار التوفيتق بين آراء الدول المختلفـة وذلك بأن ألزمـت في المـادة (82) فقـرة (1) منها الدول الساحلية بتقديم مدفوعات مالية أو مساهمات عينية لقاء استغلال الموارد غير الحية للجـرف القـاري وراء المـائتي ميـل بحـري مـن خطوط الأسـاس التي يقـاس منهـا عـرض البحر الإقليمي (22)

\section{- تحديد الجرف القاري طبقاً لقاعدة خط الوسط}

استقر الوضع بـين الـدول على أنه في حالـة وجـود جـرف قـاري بـين دولتين سـاحليتين

متقابلتين أو متجاورتين فإن ما تختص به كل منهما يتحدد بالاتفاق بينهما (23) فإن لم يكن فيكن هناك اتفاق خاص ولم تقض ظروف خاصة التحديد على وجه آخر فإنه يطبق المعيار الذي أتت بـه المـادة السادسة مـن اتفاقيـة جنيف لعـام 1958م للجرف القـاري وهو معيـار الخطط الأوسط الذي تقع كل نقطة منها على أبعاد متساوية من أقرب النقط التي يبدأ منها قياس البحر الإقليمي لكل منها وفي حالة الدول الساحلية المتجاورة تطبق أيضاً قاعدة المسافات المتساوية وهي مسافات متساوية من أقرب نقاط تقع على خط الأساس الذي يحسب منه لئه عرض البحر الإقليمي لكل من الدولتين ومما بتحر الإشارة إليه أن تطبيق هاتين القاعدتين

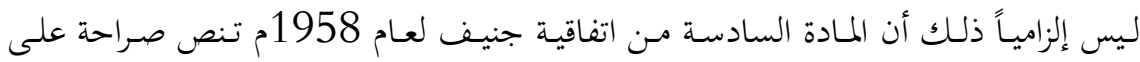
إمكان الاتفاق على ما يخالفها إذا دعت إلى ذلك ظروف خاصة كما لو كان هناك انبعاج

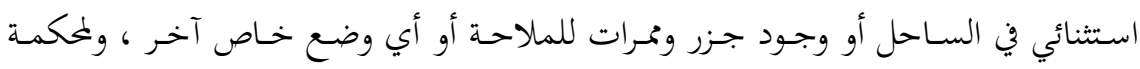


العـل الدولية حكم مهمم يوضـح كيفيـة تطبيق المعيـار السـابق لتحديـ الجـرف القـاري وهـذا الحكم كان قد صدر في 1969/2/20م وهو يتعلق بقضية الجرف القاري في بحر الشمال وفيه توصلت المحكمة إلى أن ألمانيا الاتحادية ليست ملزمة بإتباع قاعدة المسافات المتساوية في رسم الحمدود مع الدانمارك وهولندا فيمـا يختص بالجـرف القـاري في بحر الشـمال كمـا أضـافت المحكمة أن هذه القاعدة قد تؤدي إلى مخالفة العدالة بالنسبة لبعض الظروف الجغرافية كما لو

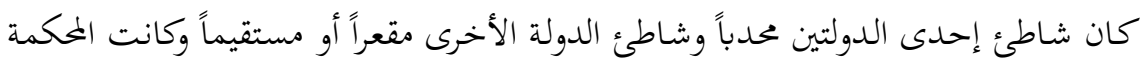
قد توصلت إلى عدة اعتبـارات يجب مراعاتها عند الاتفـاق على تعيين حدود الجرف القـاري مثل الاتحاه العام لشاطئ كل دولة وملامحه إلى جانب تكوين الجرف القاري فضلاً عن إيجاد تناسق بين حسدود الجـرف القـاري وبين طول شـاطئ كل دولة ولعل أهم مـا أبرزته المحكمة

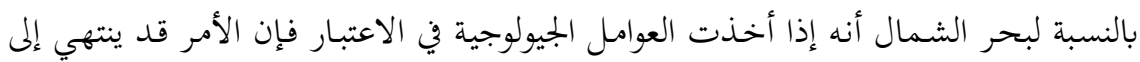
تداخل مناطق الجرف القـاري لأن المعيار الجغرافي الخاص قد يقسم حقل زيت أو غـاز على نهو يجعل الاستثمار المنفصل مستحيلاً أو مفيداً فقط لأول مستثمر فإذا كان هذا هو الحسال فبإن المحكمة تقـترح بأن يقوم الطرفـان باستثمار مشترك طالما أن هذا الاستثمار هـو الطريقة الوحيدة المناسبة إذا ما أريد الاحتفاظ بوحدة الموقع (24). المبحث الثالث : النظام القانون للجرف القاري لماكان الجرف القاري ما هو إلا جزء من إقليم الدولة ولو أنه مغمور بمياه أعالي البحار كان من الطبيعي أن تكون حقوق الدولة الساحلية على هذا الجرف هي ذات الحقوق التي تمارسها الدولة على إقليمها وذلك في النطاق الذي تتيحه ظروف الطبيعة في هذه الحالة وهو ما أكدته المادة الثانية من اتفاقية جنيف لعام 1958م للجرف القاري عندما قررت في فقرتا الأولى أن “، .. الدولة الساحلية تمارس على الجرف القاري حقوق سيادة Sovereign) Rights) المادة أن حقوق الدولة الساحلية على الجرف القاري حقوق انفرادية وعلى ذلك إذا لم تقم

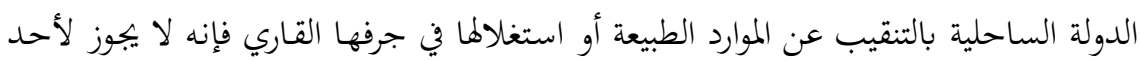
آخر أن يقـوم بهـا النشـاط في جرفها القـاري أو أن يـدعي حقـاً في نطاقه مـا لم يكـن ذلك بموافقة الدولة الساحلية ذاقا ولتأكيد تبعية الجرف القاري للدولة الساحلية بصرف النظر عن 
وجـود وضـع اليـــ أو فقدانـه أو الإعـلان عـن هـــه التبعيـة قـررت الفقـرة الثالثـة مـن المـادة الثانية،"...أن حقوق الدولة الساحلية على الجرف القـاري لا تتوقف على وضع يدها عليه فعلياً أو افتراضياً كما لا تتوقف على أي إعلان صريح هذا وإذا رغبت دولة أجنبية في القيام بأبحاث علمية في الجرف القـاري الخاص بدولة ساحلية أخرى فلابد مـ موافقـة هذه الدولة الأخـيرة وبالتمعن في نـص المـادة الثانيـة مـن اتفاقيـة جنيـف لعـام 1958م للجـرف القـاري يتضح أن حقوق السيادة التي تمارسها الدولة الساحلية على قاع البحر وما تحته من الجرف القاري تقتصر فقط على اكتشاف الموارد الطبيعية (25) ولا يؤثر ذلك في الوضع القانوني للمياه التي تعلو هذا الجرف القاري باعتبارها بحاراً عالية كما لا يؤثر ذلك في الوضع القانوني لما فوق هذه المياه من هواء وهو ما أكدته المادة الثالثة من اتفاقية الجرف القاري لعام 1958م وبهذا تكون اتفاقية جنيف قد فصلت بين الوضع القانوبي للمياه التي تعلو الجرف القاري باعتبارها مـن البحـار العاليـة ووضـع الجـرف القـاري ذاتـه والـذي تمـارس عليـه الدولـة السـاحلية حقـوق السيادة الانفرادية وهي بذلك تكون قد وضعت حداً لما تدعيه بعض الدول مثل الأرجنتين وشيلي وبيرو والتي كانت تطالب بحقوق سيادة على الجرف القاري وكذا على المياه ذاتها التي

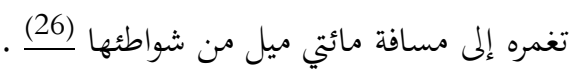
كما لجأت اتفاقية جنيف إلى تحديد الموارد الطبيعية التي تنفرد الدولة الساحلية باستغلالها في الجرف القاري وكان ذلك التحديد من جانبها تحديداً قاطعاً ذلك أفها قصرتا على الموارد الطبيعية المعدنية وغيرهـا من الموارد غير الحية إلى جانب الكائنات الحية التي تكون في طور حصادها أو غير متحركة على قاع البحر أو غير قابلة للتحرك إلا بطريق الاتصال الجثماني المستمر بالقاع أو بما تحته وملا كان هذا التحديد على سبيل الحصر فإنه يترتب على ذلك أن صسيد الأسماك في الجـرف القـاري لا يكـون مقصوراً على الدولـة السـاحلية التي يجـب عليها الامتنـاع عن التعرض لحقوق الصيد في المياه التي تغمر الجـرف القـاري أو للموارد الحية فيها واستناداً لما للدولة الساحلية مـن حقوق سيادة على جرفها القـاري فبإن من حقها أن تقيم وتدير في المياه فوق مناطق الجرف القاري مختلف المنشآت اللازمة للتنقيب واستغلال مواردها الطبيعيـة مثـل المنصـات البحريـة والجـزر الصـناعية ولهـا أن تقيم حـول هـذه المنشـآت ولمسـافة

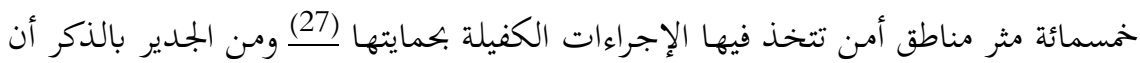


أية منشآت تقيمها الدولة الساحلية على الجرف القاري لا تتمتع بكيان الجزر الطبيعية وعلى ذلك فإنه بطبيعة الحال لا يكون لها أية مياه إقليمية خاصة هما كما يجب ألا يكون لوجودها لهاريا

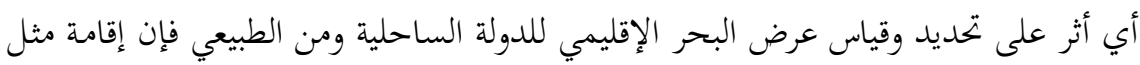

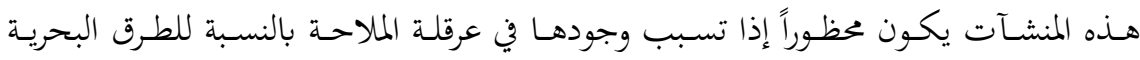

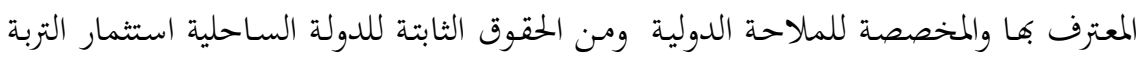
المغمورة بقاع البحر عن طريق حفر الأنفاق بصرف النظر عن عمق المياه فوق التربة المغمورة

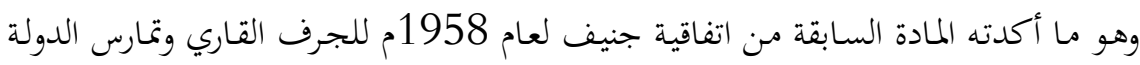

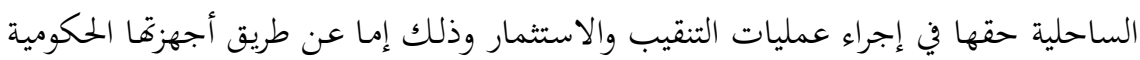

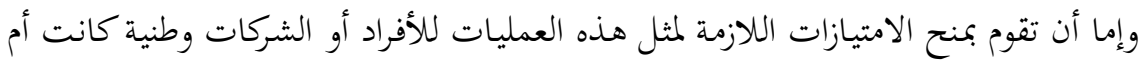
أجنبية (28)

- الجرف القاري واتفاقية الأمم المتحدة لقانون البحار لعام 1982

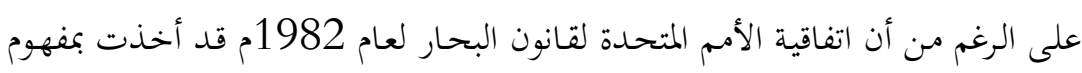

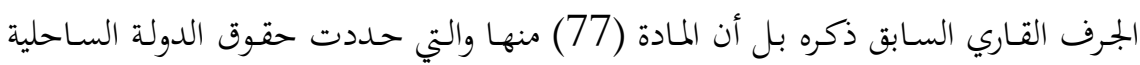

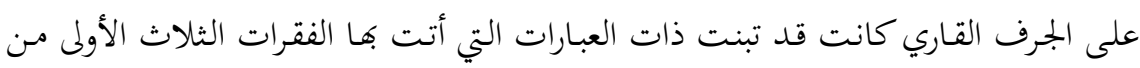

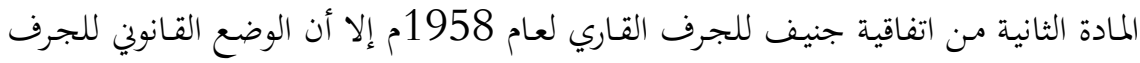

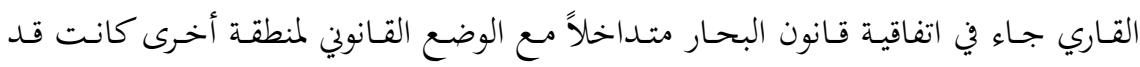

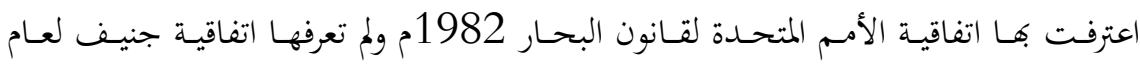

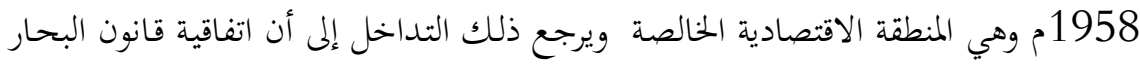

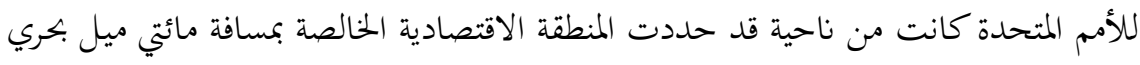

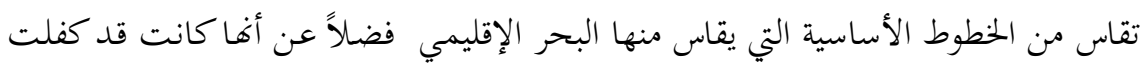

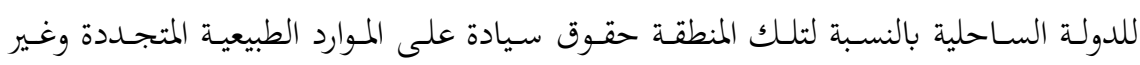

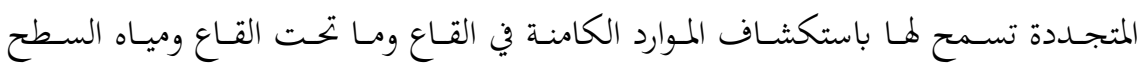

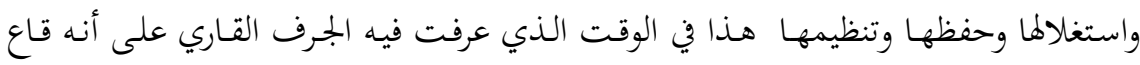

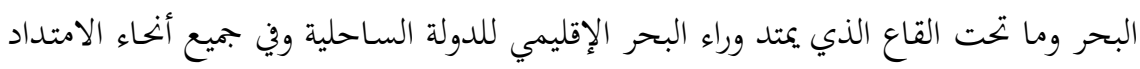

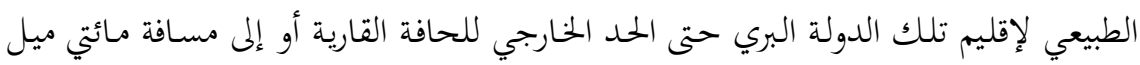


بحـري مـن الخطوط الأساسـية التي يقـاس منهـا عـرض البحـــ الإقليمسي إذا لم يكـن الطـرف الخارجي للحافة القارية يمتد إلى تلك المسافة (م 1/76) (29) . ومن هذا يتضح أن اتفاقية الأمم المتحدة لقانون البحار لعام 1982م تمتد بحقوق الدولة الساحلية وولايتها على سطح المياه إلى مائتي ميل باسم المنطقة الاقتصادية الخالصة كما يمتد الامتـاد ذاته في قاع البحر ومـا تحت القـاع باسم الجمرف القـاري ومـن ناحية أخرى كفلت اتفاقية قانون البحار للأمم المتحدة للدولة الساحلية بالنسبة للمنطقة الاقتصادية حقوقاً سيادية لغرض استكشـاف الموارد الطبيعية الحيـة وغير الحيـة الموجودة في باطن الأرض والميـاه العلوية

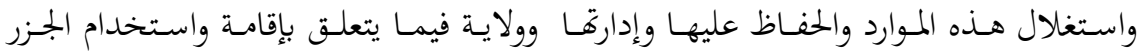
الصناعية والمنشآت والتركيبات كما كفلت لما ولاية فيما يتعلق بالبحث العلمي البحري وحماية البيئة هذا في الوقت الذي كفلت فيه للدولة السـاحلية حقوقاً على امتـادها القـاري بقصد استكشاف واستثمار الموارد الطبيعية واعتبرت هذه الحقوق انفرادية خالصة تتمتع بهـا الدولة الساحلية دون تعليق ذلك على حيازة فعلية أو رمزية أو حتى إعلان صريح من جانبها وقد كان مـن تشـابه الحقوق التي كفلتها اتفاقيـة الأمـم المتحـدة لقـانون البحـار للدولة السـاحلية بالنسبة لكل من المنطقة الاقتصادية والجرف القاري فضلاً عن تساوي المسافات التي حددت بها كلتا المنطقتين مائتي ميل أن ذهب البعض إلى القول بأن الجرف القاري للدولة الساحلية

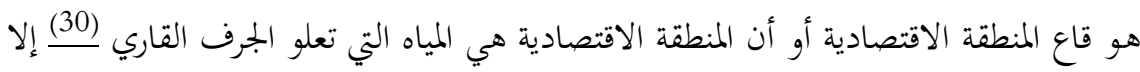
أن هذا الرأي الأخير يتعارض مع مضمون اتفاقية الأمم المتحدة لقانون البحار والذي ينطوي على احتمالات عدم تطابق المنطقة الاقتصادية مع الجرف القاري من حيث المسافة أي عندما يكون الجرف القـاري في مفهومـه الجغرافي متجاوزاً لحد المائتي ميل من ساحل الدولة وهو ما تعرضت لـه صراحة المادة (82) من اتفاقية الأمهم المتحدة لقـانون البحار عندما اعترفت بأن للدولة الساحلية الحق في استغلال الموارد غير الحية لجرفها القاري وراء المائتي ميل بحري وذلك مقابل تقديم مدفوعات مالية أو مساهمات عينية وقد نصت الفقرة (4) من المادة (82) على أن تقـدم تلك المـدفوعات أو المسـاهمات إلى السـلطة الدوليـة التي تتـولى توزيعها على الـدول الأطراف في هـذه الاتفاقيـة على أسـاس معـايير التقاسـم المنصف آخـذه في الاعتبـار مصـالح الدول النامية واحتياجاها ولاسيما الدول الأقل نمواً وغير الساحلية منها (31). 
الحخاتمة

لقد عرفت المادة (76) من اتفاقية الأمم المتحدة لقانون البحار الجرف القاري بالقول على أن ". .. يشمل الجـرف القـاري لأي دولة ساحلية قاع وباطن أرض الساحات المغمورة التي تمتد إلى ما وراء بحرها الإقليمي في جميع أنحاء الامتداد الطبيعي لإقليم تلك الدولة البري حتى الطرف الخارجي للحافة القارية أو إلى مسافة مائتي ميل بحري من خطوط الأساس التي يقاس منها عرض البحر الإقليمي إذا لم يكن الطرف الخارجي للحافة القارية يمتد إلى تلك المسافة ..." . وهكـا يشـمل الجـرف القـاري للدولـة الشـاطئة قـاع البحـر ومـا تحته فيمـا وراء بحرهـا الإقليمي على طول الامتداد الطبيعي للإقليم البري لذذه الدولة حتى الحافة الخارجية للهامش القـاري أو حتى مسـافة مـائتي ميل بحـي مـن خطوط الأسـاس التي يبـدأ منهـا قيـاس البحـر الإقليمي إذا كانت الحافة الخارجية للهامش القاري توجد على مسافة أقل وإذا وجدت الحافي الحافة الخارجية للهامش القـاري على بعد أكثر من مائتي ميل فقد نصت الاتفاقية على أن الجرف القـاري يمكـن أن يمتد إلى مسافة لا تزيـد عن مـائتي ميل مـن خطوط الأسـاس التي يبدأ منها

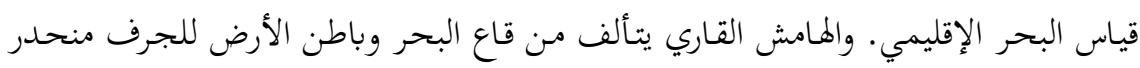

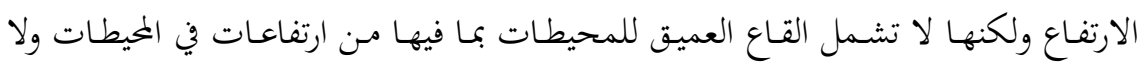
باطن أرضها ولذا فإن لكل دولة الحق في جرف قاري يتحسد بمسـافة مـائتي ميل بحري إذا كانت الحافة الخارجية للهامش أقل من هذه المسافة أو أزيد من مائتي ميل بحري وحتى ثلاثمائة وخمسون ميلاً بحرياً إذا تعدى الهامش القاري مسافة المائتي ميل. استقر الوضع بين الدول على لى أنه في حالة وجود جرف قاري بين دولتين ساحليتين متقابلتين أو متجاورتين فإن ما تختص به كل منهما يتحدد بالاتفاق بينهما، فإنان لم يكن هناك اتفاق خاص ولم تقض ظروف خاصة التحديد على وجه آخر فإنه يطبق المعيار الذي أتت به المادة السادسة من اتفاقية جنيف لعام

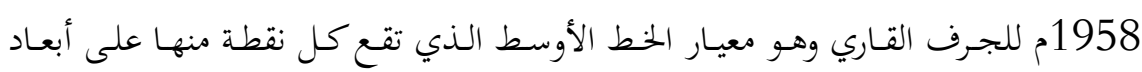
متساوية مـن أقرب النقط التي يبـأ منها قيـاس البحر الإقليمي لكل منها وفي حالة الدول

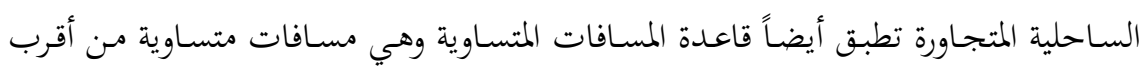
نقاط تقع على خط الأساس الذي يحسب منه عرض البحر الإقليمي لكل من الدولتين ومما تجدر الإشارة إليه أن تطبيق هاتين القاعدتين ليس إلزامياً ذلك أن المادة السادسة مـن اتفاقية 
جنيف لعام 1958م تنص صراحة على إمكان الاتفاق على ما يخالفها إذا دعت إلى ذلك ظروف خاصة كما لو كان هناك انبعاج استثنائي في الساحل أو وجود جزر وممرات للملاحة أو أي وضع خـاص آخر. وملاكـان الجرف القـاري مـا هو إلا جزء مـن إقليم الدولة ولو أنه مغمور بمياه أعالي البحار كان من الطبيعي أن تكون حقوق الدولة الساحلية على هذا الجرف هي ذات الحقوق التي تمارسها الدولة على إقليمها وذلك في النطاق الذي تتيحه ظروف

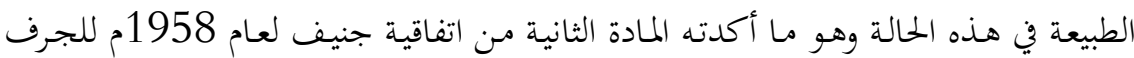

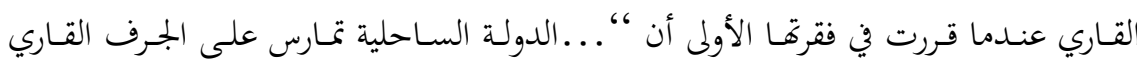
حقوق سيادة بقصد التنقيب عن الموارد الطبيعية واستغلالما كما أن حقوق الدولة الساحلية على الجرف القاري حقوق انفرادية فإذا لم تقم الدولة الساحلية بالتنقيب عن الموارد الطبيعة أو استغلالما في جرفها القاري فإنه لا يبجوز لأحد آخر أن يقوم بهذا النشاط في جرفها القاري أو أن يدعي حقاً في نطاقه ما لم يكن ذلك بموافقة الدولة الساحلية ذاقا. المصادر والهوامش

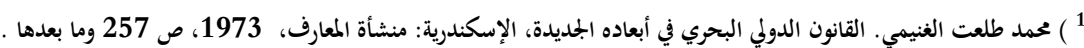

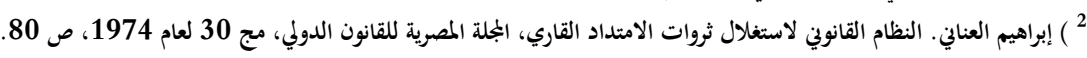
3 ) Borchard, E., Resources of the Continental Shelf, AJIL, Vol 40 , 1946 , P. 853

${ }^{4}$ ) Whiteman M., Digest of International Law , Vol , 4, 1965 , P. 233

5 ) Emery K., Geological Limits of the Continental Shelf, Ocean Development and International Law , Vol .10 , 1981 , P. 1 .

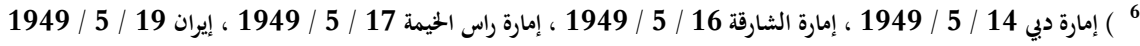

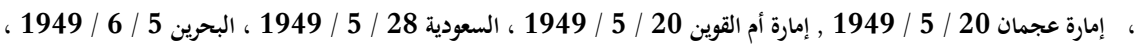

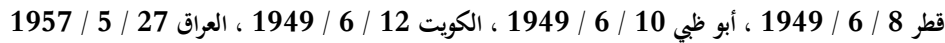

Al- Hakim A., The Middle Eastern and the law of the Sea , Manchester University Press, 1979 , P. 95 et seq

${ }^{7}$ ) Gutterdge M., The 1958 Geneva Convention on Continental Shelf, BYBIL, Vol. 27, 1959, P.102

8 ) Rhee S., Sea Boundary Delimitation Between States Before World War II , AJIL , vol. 47, 1982, P. 555 et seq

9 ) Anderson, D., Some Recent Developments in the law Relating to the Continental Shelf, Journal of Energy and Natural Resources Law, Vol. 6, 1988, P. 95

10 ) حامد سلطان . القانون الدولي العام ، القاهرة : دار النهضة العربية , 1962 ، ص 653 وما 658 وما بعدها.

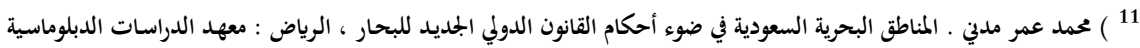

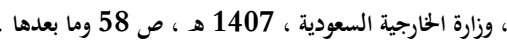


12 ) عمر بن أبو بكر باخشب. القانون الدولي العام للبحار في أبعاده الجديدة ، جدة : دار حافظ ، 1412 هـ ، ص ص 69 ه وما بعدها .

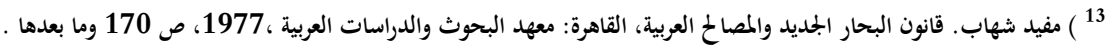

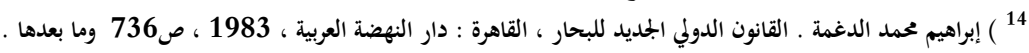

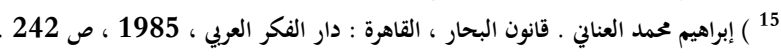

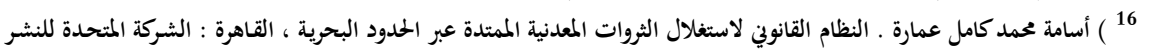

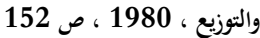

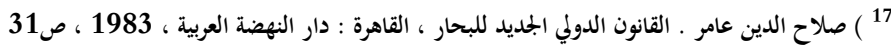

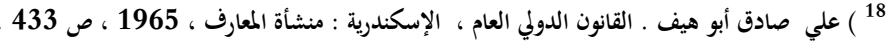

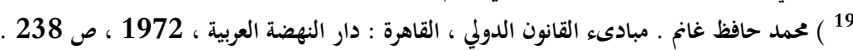
${ }^{20}$ ) ICJ Reports , 1969 , P. 100

$$
21 \text { ) إبراهيم محمد الدغمة . مصدر سابق ، ص } 206 \text { حسن } 206
$$

22 حسين ندا حسين . الأهمية الاستراتيجية والنظام القانوبي للطريق البحري في الخليج ، بغداد : منشورات وزارة الثقافة والإعلام ،

1980

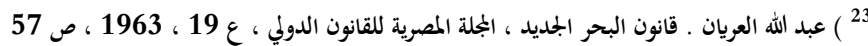

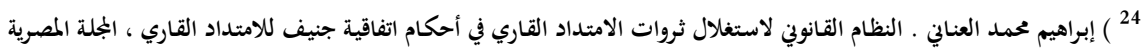

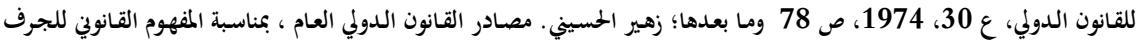
القاري وطرق قياس حدوده بين الدول المتلاصقة والمتقابلة، بنغازي: منشورات جامعة قاريونس،

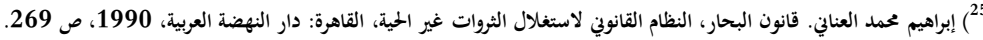

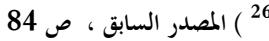
27 مفيد شهاب ـ النظام القانوني لمياه البحر الأممر ، ندوة البحر الأحمر ، الرياض : معهد الدراسات الدبلوماسية ، وزارة الحخارجية

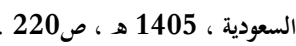
28 28 ${ }^{29}$ ) Knight G., Law of the Sea Cases, Documents and Reading, Washington D.C.: Nautilus Press, 1976 ,P. 344.

30

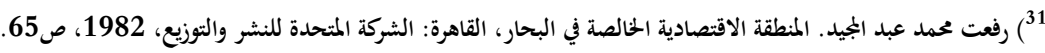

